\title{
Trends and Extremes Analysis of Daily Weather Data from a Site in the Capitanata Plain (Southern Italy)
}

\author{
Domenico Vitale ${ }^{* 1}$, Gianfranco Rana ${ }^{2}$, Pietro Soldo ${ }^{3}$ \\ ${ }^{1}$ Dipartimento di Scienze Statistiche "C. Cecchi”, Università degli Studi di Bari \\ Via Camillo Rosalba 53, 70124 Bari, Italy \\ ${ }^{2}$ CRA-SCA - Unità di Ricerca per i Sistemi Colturali degli Ambienti caldo-aridi \\ Via Celso Ulpiani 5, 70125 Bari, Italy \\ ${ }^{3}$ Consorzio per la Bonifica della Capitanata \\ Corso Roma 2, 71121 Foggia, Italy
}

Received: 3 August 2009. Accepted: 17 December 2009.

\begin{abstract}
The impacts of the climate change for agriculture is an ambitious and unresolved topic due to the complexity of the natural phenomena. The high variability of the Mediterranean basin does not allow us to generalize with enough certainty the results obtained from other researches and other locations. Therefore, a site specific analysis in Capitanata plain was conducted. The aim is to provide a detailed picture of recent change in climate regime in one of the most important agricultural area of South Italy. Climate analysis was carried out and several indices of extreme events were studied on the basis of temperature and precipitation observations registered at experimental station 'Podere 124' (CRA-SCA). The period under study is 1979-2008. Increasing trends were identified for the summer season with an intensification of the number of heat waves.
\end{abstract}

Key-words: Mediterranean area, climate change, time series analysis.

\section{Introduction}

The forth assessment report AR4 of the Intergovernmental Panel on Climate Change (IPCC, 2007) stated that by the end of this century the planet's average temperature is expected to rise anywhere between about 1.4 and $6{ }^{\circ} \mathrm{C}$. Although only a small fraction of this warming had happened so far, predicted effects are already becoming visible in some regions, with frequent deadly heat waves, rising sea level, strong floods and droughts, spread of tropical diseases and decline of sensitive species.

There is a common opinion in scientific debate, supported by several studies, that change in climate is unequivocal together with a growth in mean temperature since the mid-1970s (Klein Tank and Konnen, 2003). Considering land and ocean data for both hemispheres during the past 150 years, Jones et al. (2009) estimated the following trends: (i) a marked warming up to 1940 , (ii) a relatively steady conditions up to the mid1970s and (iii) a subsequent rapid warming. Hansen et al. (2006) affirmed that global surface temperature increased of about $0.2^{\circ} \mathrm{C}$ per decade in the past 30 years. Gil-Alana (2008) found that the highest increase took place during the last twenty or thirty years, i.e. 2.37 ${ }^{\circ} \mathrm{C} / 100$ years in the northern hemisphere and about $1.30{ }^{\circ} \mathrm{C}$ for the southern one.

Even if the increase in mean temperature is primarily caused by increase in night temperature, it was shown that not all regions are answering in the same way to the rise of global mean temperature: one of the must critical region is the Mediterranean basin, where a non uniform and discontinuous warming was identified and a marked east-west differentiation in temperature trends was well documented (Kostopoulou and Jones, 2005). Concerning Italy, Brunetti et al. (2000; 2004) pointed out that the trend in temperature is the greatest in

\footnotetext{
* Corresponding Author: Tel.: +39 080 5475026; Fax: +39 080 5475023. E-mail: domenicovitale1981@libero.it
} 
the south, while for precipitations a negative trend in the number of wet days and/or the total rainfall amounts was found, but with an increase in intense precipitation events over the period 1951-2000.

Furthermore, global warming is likely affecting the climate variability, with increased probability and intensity of extreme weather events. The term "extreme" means "individual weather event which is unusual in its occurrence" (i.e. heat wave, frost days, droughts, etc.) or having destructive potential, such as hurricanes and tornadoes. For these reasons, changes in extreme weather and climate events have significant impacts and are among the most serious challenges to society, economy and natural ecosystem. Easterling et al. (2000) reported that the frequency of climate extremes in temperature and precipitation is expected to increase during the current century. These events, such as late spring frost, windstorm, extremely hot weather, severe drought or prolonged soil wetness coinciding with hot weather, can cause serious damage to the natural and agricultural crops because they have little difficulty to accommodate moderate changes in typical weather, but changes in the tails of the distribution (the extremes) cannot be so easily recovered, since they have often very direct impacts (Peterson et al., 2008).

The analysis of climate trends and mainly of extreme events is often carried out at very local space scale, by studying the time series calculated at a single site (see for example Parmesan et al., 2000; Beniston and Stephenson, 2004; Beniston and Diaz, 2004; Kostopoulou and Jones, 2005). On the other hands, the extreme events statistics need to be processed at small scale for fully understanding the uncertainty of the applied models (Katz, 2002; Baigorria et al., 2007).

Given the aforementioned scenarios, in this study we examine the climate variability of the last thirty years in the Capitanata plain, one of the most important agricultural area of South Italy. This contribution deals with several aspects of mostly empirical, static, data analysis with the goals to provide a consistent picture of the local climate variability and to identify trends. Therefore, after the application of quality control procedures and the homogeneity tests, we analyzed the climatology and the water and heat regime in an experimental station representing this area in the period 1979-2008. Rigorous and robust statistical tests were applied to temperature and precipitation series and several indices were analysed to look for a trend in the frequency and/or severity of weather extremes. Our aim is to offer an effective, clear and suitable picture of the local climate changes in the agricultural area of the Capitanata, in order to suggest scientists and stakeholders useful tools for the comprehension and best analysis of the present and future scenarios.

\section{Material and methods}

Local climate is an intricate and chaotic system responding to a great number of solicitations, some of them correlated to large scale patterns, such as the North Atlantic Oscillation (NAO), and others representative of local (micro) variability. Further and unfortunately, weather observations are susceptible to a number of potential errors and for this reason, preliminarily to any analyses, it is needed to perform accurate data quality control check, whatever was the purpose of investigation.

In this section (i) firstly, a description of time series used in the further analyses is given, supported by a brief explanation of the quality control procedures adopted and the homogeneity tests preliminarily performed to guarantee the high-quality of data for the climate change studies. (ii) The Walter and Lieth (1960) climate diagram, useful to understand the climate dynamics between temperature and precipitation of the interest area, is described. (iii) The trend analysis procedures were outlined, both at monthly and annual basis, in order to quantify and to compare it with other results in literature. (iv) Finally, the extreme event indices applied to the daily series and useful to better understand the change in climate dynamics were described.

\subsection{Historical daily data, quality control and ho- mogeneity test}

The daily minimum temperature (Tmin), maximum temperature (Tmax) and precipitation (Prec) series registered at the agro-meteorological station 'Podere 124' of the CRA-SCA (lat. $41^{\circ} 26^{\prime} 49^{\prime}$ ", long. $15^{\circ} 30^{\prime} 15^{\prime}$ ", alt. $90 \mathrm{~m}$ ) located in the Apulian Tavoliere were analysed (Fig. 1). The daily dataset covers the period from Janu- 


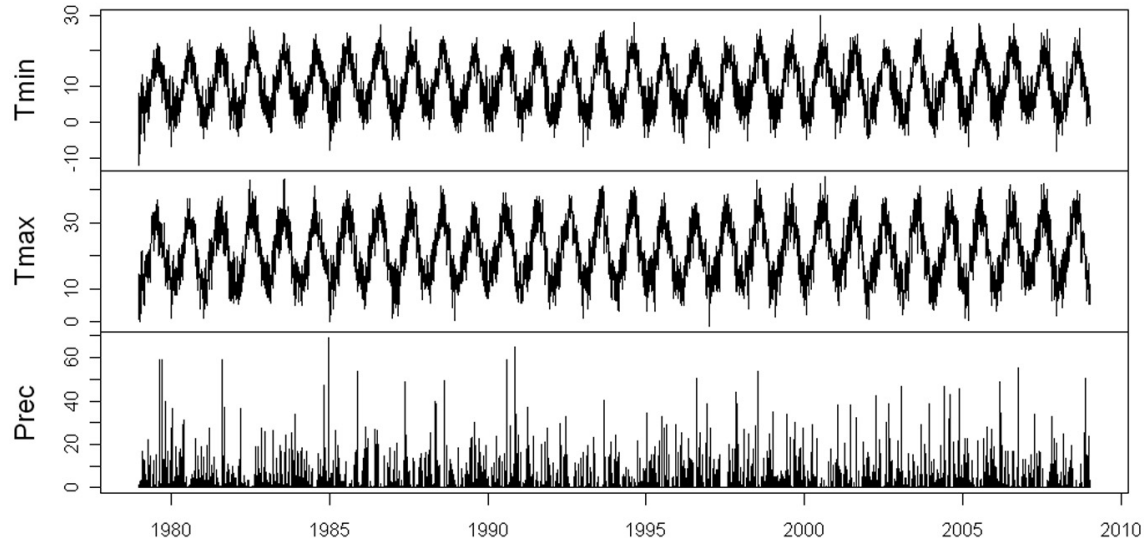

Figure 1. Minimum, maximum temperatures and precipitation daily series registered at 'Podere 124' (Capitanata, Italy) during the period 1979-2008. ary 1979 up to December 2008, so as to meet the World Meteorological Organization (WMO) recommendations that considers a minimum period of three decades for the climatic analysis.

Additional quality control (QC) of the daily data were undertaken using both the procedures proposed by Rana et al. (2004) and Zhang and Yang (2004) implemented in R software package RClimDex. The QC consisted of preliminary checks for identifying consistency errors (e.g., $-20^{\circ} \mathrm{C}<\mathrm{Tmin}<\operatorname{Tmax}<50{ }^{\circ} \mathrm{C}, 0 \mathrm{~mm}$ $<$ Prec $<300 \mathrm{~mm}$ ) resulted, for example, by the digitalization of character manually recorded, random errors arisen from electronic noise in measurements, sensor degradation and, sometimes, untraceable causes. The thresholds for defining an outlier were set to be three times the standard deviation $(\sigma)$ of daily Tmin and Tmax records and six $\sigma$ for daily precipitation data. Potential errors were then validated or rejected by consulting (i) the original records on paper archive, (ii) the values of adjacent days at the same station, (iii) data from the same date at nearby stations from the Servizio Idrografico Nazionale and the Consorzio per la Bonifica della Capitanata networks. Only those values that were positively found to be erroneous were set to "missing" and deleted from following analyses.

After the QC step, each series were statistically tested with respect to homogeneity, following the procedures adopted by the European Climate Assessment \& Dataset (Wijngaard et al., 2003; Klein Tank, 2008). After an accurate study and analysis, three test methods were selected to evaluate the departure of homogeneity in the time series: the standard normal ho- mogeneity test (SNHT) for a single break (Alexandersson, 1986), the Buishand range test (Buishand, 1982) and the Pettitt test (Pettitt, 1979). After an huge work for founding the most useful variables to be analysed, the testing variables chosen to be used in the analysis were (i) the annual mean of the diurnal temperature range (mDTR), (ii) the annual mean of the absolute day-to-day differences of the diurnal temperature range (vDTR) and (iii) the wet day number (threshold $0.1 \mathrm{~mm}, 1 \mathrm{~mm}$ and $10 \mathrm{~mm}$ ).

\subsection{Climate description}

In order to summaries the climatic variables and their time course in the year, the Walter and Lieth (1960) climatic diagram is considered. This diagram only use precipitation and average air temperature at monthly scale; it gives an accurate representation of the type of climate and the dynamics between used variables. This climatic diagram is built so that $20 \mathrm{~mm}$ of monthly precipitation (right ordinate) equals $10^{\circ} \mathrm{C}$ average temperature (left ordinate), in order to individuate drought periods when the precipitation line crosses the temperature line. In addition, descriptive statistics about monthly mean values, relative standard deviations, and absolute minima and maxima values for each climate variables were reported (Tab. 2-3). Furthermore, the climate classification is carried out on the basis of the Aridity Index defined by De Martonne (1941) as the ratio between mean annual precipitation and mean annual temperature.

\subsection{Time trend estimation}

In the AR4, the word "trend" is used to designate a generally progressive change in the lev- 
el of a climatic variable. The statistical methods for determining the precise magnitude of the change, if it exists, is an unsolved topic. In fact, the probability of detecting trends in time series depends on its magnitude, the record length and the statistical properties of the interested variable, in particular the variance (Klein Tank and Konnen, 2003).

In many applications of time series analysis, trend is described as the slope of a linear function having the form

$$
y_{t}=\beta_{0}+\beta_{1} t+x_{t} \quad \text { for } t=1,2, \ldots, n
$$

where $y_{t}$ is the observed climatic series at time $t$, and $x_{t}$ is the noise term capturing the variability around the time-trend. The estimation of the slope by least square method is easy to understand and suitable statistical tools are available for estimating the uncertainty in the fitted trends arising from sampling variability. The slope parameter $\beta_{1}$ can be considered as a measure of the average change in $y_{t}$ per time period (i.e. if $\beta_{1}=0.1$ means an increase of $0.1{ }^{\circ} \mathrm{C}^{*} 10$ years $=1{ }^{\circ} \mathrm{C}$ per decade) and its significance can be tested by the Student's t test.

Nevertheless, there are some instances when least-squares methods may be sensitive to individual values, such as a single outlying observation that lies near either the beginning or the end of the available data record. Such observations have "high leverage", meaning that the fitted trend can be strongly affected by their inclusion or exclusion from the data record. For this reason, non-parametric methods for detecting trends may be a challenge because more statistically robust, in particular when the distribution is non Gaussian (Klein Tank at al., 2009).

The primary testing for trends in this study is conducted using both regression analysis and the non parametric Mann-Kendall test (Kendall, 1938, Mann, 1945) for correlation, commonly used for climatic variables (Sneyers, 1990). The annual mean of daily minimum and maximum temperature and the annual amount of daily precipitation series were chosen for testing procedure.

Because climate system contains variability at all time scales and a possible changes in the individual month may be substantially different from changes in annual mean, the MannKendall test was also performed to search for a tendency at monthly basis.

\subsection{Extreme weather indices}

Climatologists suggested a number of indices of climate extremes which can be easily calculated. There are two main categories of extremes indices: those based on absolute thresholds and those based on percentiles. The first category refers to the annual count of days crossing a specified absolute value (e.g., the frost day index counts days with $\mathrm{Tmin}<0{ }^{\circ} \mathrm{C}$ ), while the second category is based upon the statistic distribution of a climatic variable. The first indices are less suitable for spatial comparisons of extremes than those based on percentile thresholds, which are expression of anomalies relative to the local climate.

The climate extreme indices are determined on the base of daily maximum and minimum temperature and daily precipitation. We used $\mathrm{R}$ software and the regional climate change package RClimDex (Zhang and Yang, 2004) for computing all 27 core indices recommended by the $\mathrm{CCl} / \mathrm{CLIVAR}$ Expert Team for Climate Change Detection Monitoring and Indices (ETCCDMI). Our statistical trend analysis focus on indices able to evaluate the extreme and intense events in the Mediterranean basin. They are listed in Table 1, their units and the commonly used abbreviations are also summarized. Since the minimum recommended length for this kind of analysis is at least thirty years, the whole period of the available daily data was set as base period for determining the frequency distribution of the index based on percentiles.

Also in this kind of analysis, the detection trend procedure was performed using both least square method and the non parametric MannKendall test.

\section{Results and discussion}

The QC step does not give evidence for a great number of erroneous values. However, the few suspect observations (only for temperature series) were removed from the set in order to not affect the following analysis. We did not proceed in estimating it: this does not represent a big problem for the analyses at monthly or annual scale because averaged values can be considered reliable even if some daily values are missing. Concerning analysis at daily scale some doubts can raised if the missing value should be 
Table 1. List of climate extreme indices.

\begin{tabular}{|c|c|c|}
\hline Index & Definitions & Unit \\
\hline \multicolumn{3}{|c|}{ Temperature } \\
\hline DTR & Monthly mean difference between Tmax and Tmin & ${ }^{\circ} \mathrm{C}$ \\
\hline TR20 & Annual count of tropical nights when Tmin $>20^{\circ} \mathrm{C}$ & days \\
\hline FD0 & Annual count of frost days when Tmin $<0{ }^{\circ} \mathrm{C}$ & days \\
\hline TX25 & Number of days when Tmax $>25^{\circ} \mathrm{C}$ & days \\
\hline TX35 & Number of very hot days when $\operatorname{Tmax}>35^{\circ} \mathrm{C}$ & ${ }^{\circ} \mathrm{C}$ \\
\hline TNX & Monthly maximum value of daily Tmin & ${ }^{\circ} \mathrm{C}$ \\
\hline TN90p & Percentage of warm nights when Tmin $>90^{\text {th }}$ percentile & $\%$ \\
\hline TX90p & Percentage of warm days when Tmax $>90^{\text {th }}$ percentile & $\%$ \\
\hline WSDI & $\begin{array}{l}\text { Warm Spell Duration Indicator. Annual count of days with at least } 6 \\
\text { consecutive days when Tmax }>90^{\text {th }} \text { percentile }\end{array}$ & days \\
\hline \multicolumn{3}{|c|}{ Precipitation } \\
\hline $\mathrm{RX} 1$ & Monthly maximum 1-day precipitation & $m m$ \\
\hline SDII & Simple daily Intensity Index (annual total/number of wet days $>0.1 \mathrm{~mm}$ ) & $\mathrm{mm} / \mathrm{d}$ \\
\hline R10 & Annual count of heavy precipitation days when Prec $>=10 \mathrm{~mm}$ & days \\
\hline $\mathrm{R} 20$ & Annual count of very heavy precipitation days when Prec $>=20 \mathrm{~mm}$ & days \\
\hline CDD & Maximum number of consecutive dry days with Prec $<1 \mathrm{~mm}$ & days \\
\hline R95p & Annual total of very wet days when Prec $>95^{\text {th }}$ percentile & $\%$ \\
\hline
\end{tabular}

replaced by an extreme event for example. On the other hand, the estimation of extreme events is a topic not easy to be solved.

In Figure 2, the results of the SNHT, the Buishand range and the Pettitt tests applied to the mDTR of 'Podere 124' are shown. The value of statistics of the three tests does not give us any indication about a break in the period taken into consideration. Thus, the null hypothesis that the annual values of the testing variable are independent and identically distributed can not be rejected at the 0.01 significance level. Figure 3 shows the results of the Buishand range test applied to the precipitation testing variable (number of wet days) with different thresholds. As shown in the figure, also for precipitation series there is no evidence for lack of homogeneity except for the $0.1 \mathrm{~mm}$ threshold curve, from which a slightly departure around 2001 is noticeable. However, day count over threshold of $0.1 \mathrm{~mm}$ is less suitable as a testing variable (Wijngaard et al., 2003), because it is oversensitive to breaks also in low amounts. Therefore, since the main purpose of the present study is to assess the quality of precipitation data for investigating trends in wet extremes, we can conclude that the series under study can be considered as homogeneous.

In the following we illustrate:

(i) the climate diagram and the descriptive statistics of climate series, (ii) the results of the trend analysis focused on decadal change, (iii) the trends of daily temperature and precipitation extremes.

\subsection{Climatology}

Concerning the climate of the last thirty years at 'Podere 124', the dry season, in which the precipitation curve undercuts the temperature curve, runs from May up to September (Fig. 4). The annual average temperature is $15.9^{\circ} \mathrm{C}$ ranging from a maximum of $32.6{ }^{\circ} \mathrm{C}$ in July and August, likely due to the effect of the sea on climate, and a minimum of about $2.8{ }^{\circ} \mathrm{C}$ in February.

The monthly average minimum and maximum temperatures and their statistics are reported in Table 2. In general, the Tmin does not assume values below the $0{ }^{\circ} \mathrm{C}$. Tmax mean is 30 ${ }^{\circ} \mathrm{C}$ during the summer season. Furthermore, $\mathrm{Au}$ gust presented the minimum variability for Tmin and the maximum variability for Tmax. The spring months, the most important period for crop growth, also showed high variability likely due to extreme frost events.

Annual precipitation (Fig. 1) is $504 \mathrm{~mm}$ in average, ranging from the $670 \mathrm{~mm}$ in 2002 to $279 \mathrm{~mm}$ in 2000 . The $41.3 \%$ of annual rain is concentrated during the autumn-winter period, from October to January. A major issue concerns the high variability of the distribution (Tab. 3). In most cases, in fact, the one day rainfall exceed the monthly average values. It means that rains are concentred in a few days, with low 

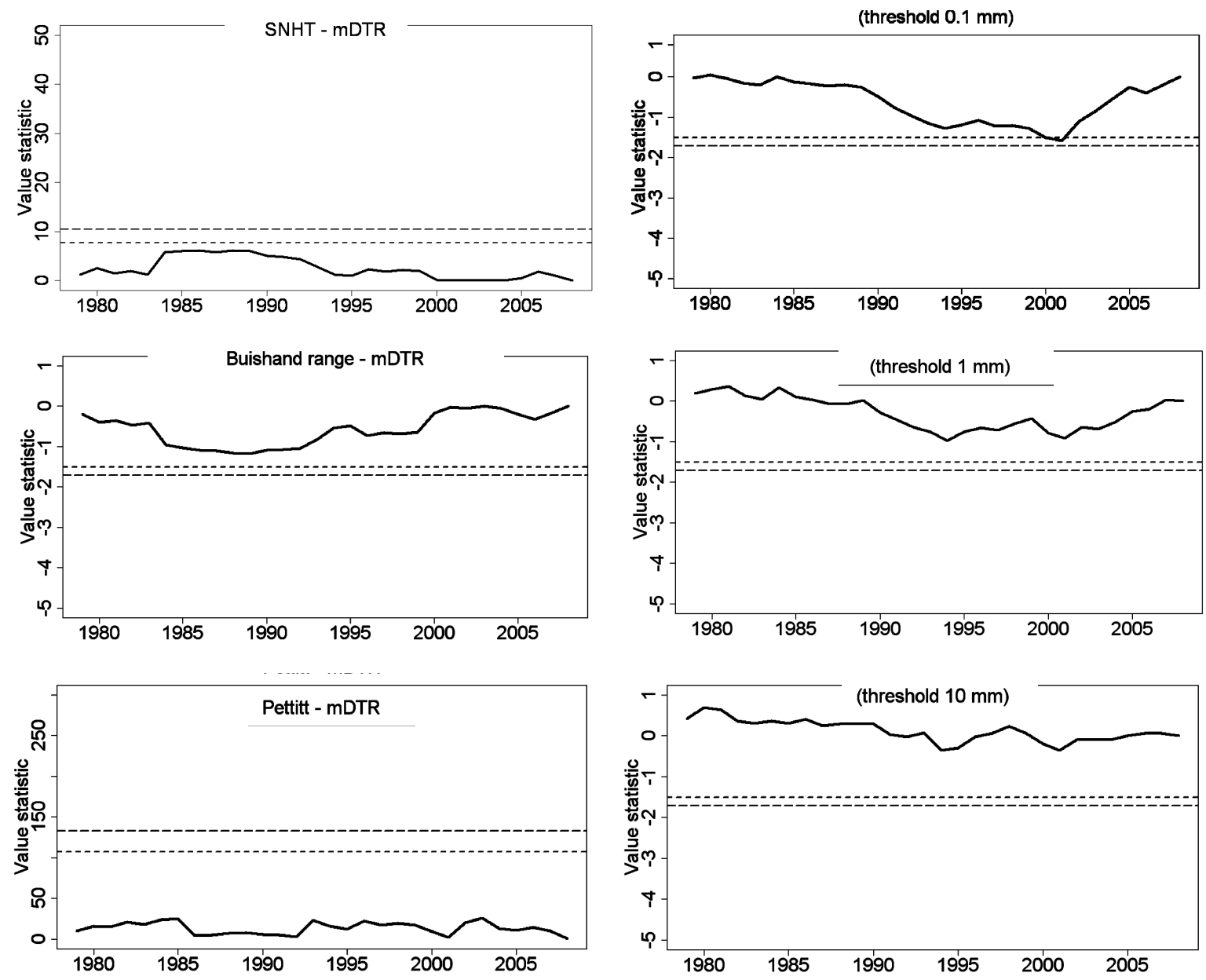

Figure 2. Test results of the SNHT (left), Buishand range (middle) and Pettitt test (right) applied to the mDTR series of station 'Podere 124' (Capitanata, Italy). Long dashed lines give $1 \%$ critical values; dashed lines give $5 \%$ critical values.

Figure 3. Test results of the Buishand range test applied to the annual wet day count series at station 'Podere 124' (Capitanata, Italy), with thresholds of 0.1 (left), 1 (middle) and $10 \mathrm{~mm}$ (right). Long dashed lines give 1\% critical values; dashed lines give $5 \%$ critical values.

Table 2. Monthly air temperatures: averages and respective standard deviations, minima and maxima values. Period: 19792008.

\begin{tabular}{|c|c|c|c|c|c|c|c|c|}
\hline \multirow[t]{2}{*}{ Month } & \multicolumn{4}{|c|}{$\operatorname{Tmin}\left({ }^{\circ} \mathrm{C}\right)$} & \multicolumn{4}{|c|}{$\operatorname{Tmax}\left({ }^{\circ} \mathrm{C}\right)$} \\
\hline & Avg & $\sigma$ & Min & Max & Avg & $\sigma$ & Min & Max \\
\hline Jan & 3.20 & 1.37 & 0.01 & 6.15 & 11.55 & 1.60 & 8.62 & 15.25 \\
\hline Feb & 2.84 & 1.34 & 0.07 & 5.59 & 12.36 & 1.85 & 7.94 & 15.61 \\
\hline Mar & 4.81 & 1.72 & 0.70 & 10.11 & 15.64 & 2.00 & 11.32 & 20.89 \\
\hline Apr & 7.10 & 1.47 & 2.87 & 9.23 & 19.02 & 1.79 & 15.18 & 21.82 \\
\hline May & 11.70 & 1.52 & 8.72 & 14.42 & 24.85 & 2.12 & 19.65 & 28.27 \\
\hline Jun & 15.80 & 1.15 & 13.73 & 18.16 & 29.70 & 1.75 & 26.28 & 33.07 \\
\hline Jul & 18.84 & 1.15 & 16.05 & 20.63 & 32.62 & 1.48 & 29.54 & 34.91 \\
\hline Aug & 19.33 & 1.09 & 16.92 & 21.15 & 32.60 & 2.14 & 28.04 & 36.20 \\
\hline Sep & 15.81 & 1.43 & 12.99 & 18.90 & 27.65 & 1.84 & 23.30 & 31.77 \\
\hline Oct & 12.16 & 1.35 & 9.42 & 14.65 & 22.75 & 1.62 & 19.55 & 26.27 \\
\hline Nov & 7.62 & 1.45 & 4.17 & 9.83 & 16.30 & 1.57 & 13.82 & 19.33 \\
\hline Dec & 4.57 & 1.44 & 2.04 & 7.21 & 12.49 & 1.54 & 9.21 & 15.54 \\
\hline
\end{tabular}


Table 3. Monthly rainfall and rainy days: averages and respective standard deviations (rain only), percent of monthly values on annual ones, absolute minima and maxima values, absolute maxima in one day. Period: 1979-2008.

\begin{tabular}{|c|c|c|c|c|c|c|c|c|c|}
\hline \multirow[t]{2}{*}{ Month } & \multirow[b]{2}{*}{ Avg } & \multicolumn{5}{|c|}{ Prec $(\mathrm{mm})$} & \multicolumn{3}{|c|}{ Rainy days $(>2 \mathrm{~mm})$} \\
\hline & & $\sigma$ & $\begin{array}{l}\text { Inc. } \\
(\%)\end{array}$ & Min & $\begin{array}{c}\text { Max } \\
24 \mathrm{~h}\end{array}$ & Max & Avg & Min & Max \\
\hline Jan & 45.8 & 31.5 & 9.0 & 6.2 & 150.2 & 46.6 & 5 & 1 & 10 \\
\hline Feb & 39.2 & 27.4 & 8.0 & 4.0 & 110.2 & 48.7 & 5 & 0 & 9 \\
\hline Mar & 45.2 & 29.0 & 9.1 & 1.8 & 99.5 & 36.4 & 5 & 0 & 9 \\
\hline Apr & 43.7 & 25.2 & 8.9 & 4.2 & 100.6 & 42.4 & 5 & 0 & 9 \\
\hline May & 36.9 & 28.8 & 7.5 & 0.0 & 109.8 & 49.0 & 4 & 0 & 10 \\
\hline Jun & 35.4 & 25.2 & 7.1 & 0.0 & 87.4 & 46.8 & 4 & 0 & 9 \\
\hline Jul & 20.9 & 24.7 & 4.0 & 0.0 & 76.7 & 53.9 & 2 & 0 & 5 \\
\hline Aug & 34.3 & 32.8 & 6.3 & 0.0 & 133.3 & 59.2 & 3 & 0 & 10 \\
\hline Sep & 40.1 & 26.2 & 7.8 & 2.0 & 91.9 & 59.0 & 4 & 0 & 8 \\
\hline Oct & 43.4 & 34.7 & 8.6 & 0.8 & 155 & 47.2 & 4 & 0 & 9 \\
\hline Nov & 63.1 & 40.0 & 12.7 & 7.8 & 166.8 & 65.0 & 6 & 1 & 12 \\
\hline Dec & 55.6 & 30.5 & 11.0 & 5.8 & 119.4 & 69.0 & 6 & 1 & 13 \\
\hline
\end{tabular}

Table 4. Statistics of the Mann Kendall test for trend (values in bold are statistically significant at $95 \%$ of confidence level).

\begin{tabular}{lcccccc}
\hline & \multicolumn{2}{c}{ Tmax } & \multicolumn{2}{c}{ Tmin } & \multicolumn{2}{c}{ Prec } \\
& tau & p-value & tau & p-value & tau & p-value \\
\hline Annual & $\mathbf{0 . 2 5 6 0}$ & $\mathbf{0 . 0 4 9 6}$ & 0.0875 & 0.5091 & 0.0437 & 0.7481 \\
\hline Jan & 0.0552 & 0.6815 & 0.0989 & 0.4537 & 0.1264 & 0.3353 \\
Feb & 0.1933 & 0.1386 & 0.0023 & 1.0000 & -0.0967 & 0.4644 \\
Mar & 0.0644 & 0.6300 & -0.0253 & 0.8584 & -0.0230 & 0.8724 \\
Apr & 0.1313 & 0.3176 & 0.1310 & 0.3177 & 0.0713 & 0.5925 \\
May & 0.2368 & 0.0688 & 0.2000 & 0.1249 & -0.0092 & 0.9573 \\
Jun & $\mathbf{0 . 3 7 7 4}$ & $\mathbf{0 . 0 0 3 6}$ & $\mathbf{0 . 3 4 2 5}$ & $\mathbf{0 . 0 0 8 3}$ & 0.0736 & 0.5802 \\
Jul & 0.2092 & 0.1083 & 0.1243 & 0.3443 & 0.0416 & 0.7615 \\
Aug & $\mathbf{0 . 2 5 7 8}$ & $\mathbf{0 . 0 4 7 6}$ & $\mathbf{0 . 2 5 5 2}$ & $\mathbf{0 . 0 4 9 7}$ & -0.0529 & 0.6947 \\
Sep & -0.1724 & 0.1868 & -0.0529 & 0.6947 & 0.0806 & 0.5440 \\
Oct & 0.0438 & 0.7480 & -0.0391 & 0.7753 & -0.1866 & 0.1534 \\
Nov & 0.0621 & 0.6427 & -0.0575 & 0.6685 & -0.0161 & 0.9148 \\
Dec & -0.1795 & 0.1694 & -0.0759 & 0.5681 & 0.2184 & 0.0935 \\
\hline
\end{tabular}

agronomic efficiency. From the observations of the number of rainy day $(>2 \mathrm{~mm})$, it appears that at 'Podere 124' it was rained at least twice a month, but at the same time the extreme dry events were verified at least once in all months between February and October.

The calculated value of the De Martonne index is 19.46 , it is between semi-arid and sub-humid zone classification.

\subsection{Decadal trends}

In this section we perform the procedure described in subsection 2.3. For each climate variable at annual and monthly scale, the estimated Mann-Kendall statistics was reported in Table 4. P-values suggest that the time trends are statistically significant (at $5 \%$ critical value) only in the case of annual maximum temperature. This change is likely related to an increasing trend in temperature of summer months. The application of the Mann-Kendall test at monthly series in fact shows a significant positive trend (the sign of tau statistics denotes the direction) during June and August both for maximum and minimum temperature. No statistical significant change was found in the precipitation regime.

According to the slope estimation by least square method (Tab. 5), maximum temperature

Table 5. Time trend estimation by least square method (values in bold are statistically significant at $95 \%$ of confidence level).

\begin{tabular}{lcccc}
\hline Clim.Var. & $\beta_{1}$ & Std Err & t value & p-value \\
\hline Tmin & 0.01346 & 0.01166 & 1.154 & 0.2580 \\
Tmax & $\mathbf{0 . 0 3 4 9 5}$ & $\mathbf{0 . 0 1 5 2 1}$ & $\mathbf{2 . 2 9 7}$ & $\mathbf{0 . 0 2 9 3}$ \\
Prec & 1.18200 & 2.02900 & 0.582 & 0.5650 \\
\hline
\end{tabular}




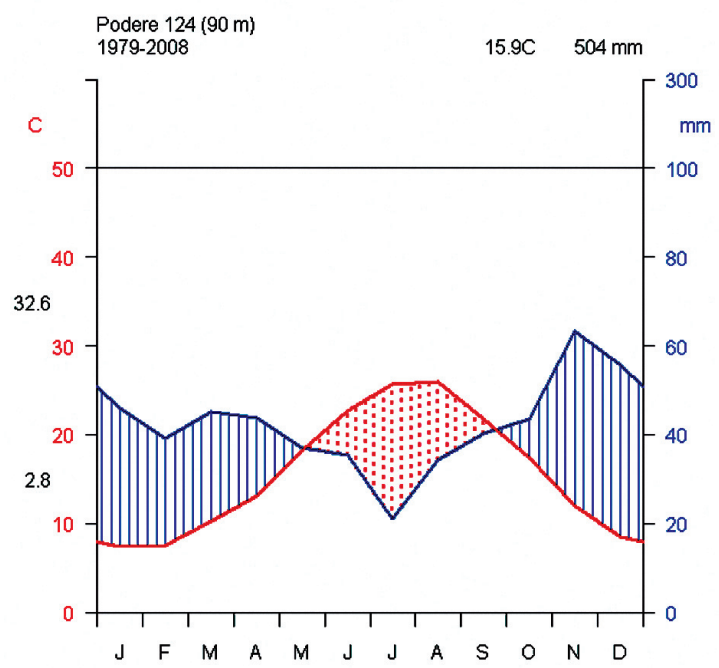

Figure 4. The Walter and Lieth climatic diagram for temperature (red line) and precipitation (blue line) series of 'Podere 124' (Capitanata, Italy). On the left axis, values in black represent the absolute maximum and minimum temperature along the whole period. On the top-right, values in black represent the averaged value of mean temperature and annual precipitation along the whole period.

have increased about $0.35{ }^{\circ} \mathrm{C}$ per decade in the last thirty years.

\subsection{Trends in extreme events}

According to the Mann-Kendall test for trend, five of fifteen indices, taken into consideration, exhibited a significant and positive trend in agreement with the global warming and in harmony to the tendencies found in the previous section, but with some more useful information about the dynamics of the local climate change. The principal results of detection trend procedure (Tab. 6) are summarize as follow:

(i) A trend of the order of $0.2{ }^{\circ} \mathrm{C}$ per decade was found in diurnal temperature range (DTR, not shown), related to the increases in the maximum temperature as it has been found in the previous analysis. This is in agreement with the results of Klein Tank and Konnen (2003) and Brunetti et al. (2004) for south Europe and in contrast to the tendency of north Europe;

(ii) About Tmin extremes, the number of frost days (FD0, not shown) does not show significant trends. This is in contrast with the results of Frich et al. (2002) in which a uniform global decrease of frost days over the
Table 6. Statistics of the linear trend fitting the extreme events and results of the Mann Kendall test (values in bold are statistically significant at $95 \%$ of confidence level).

\begin{tabular}{lccccc}
\hline Indices & \multicolumn{3}{c}{ Least square estimation } & \multicolumn{2}{c}{ Mann } \\
\cline { 2 - 6 } & Slope & Std Err & p-value & tau & p-value \\
\hline TR20 & $\mathbf{0 . 4 6 5}$ & $\mathbf{0 . 2 1 7}$ & $\mathbf{0 . 0 4 1}$ & 0.244 & 0.063 \\
FD0 & 0.173 & 0.118 & 0.153 & 0.193 & 0.147 \\
TX25 & 0.149 & 0.279 & 0.597 & 0.016 & 0.915 \\
TX35 & $\mathbf{0 . 5 8 6}$ & $\mathbf{0 . 2 0 7}$ & $\mathbf{0 . 0 0 8}$ & $\mathbf{0 . 3 3 4}$ & $\mathbf{0 . 0 1 1}$ \\
TNX & $\mathbf{0 . 0 9 8}$ & $\mathbf{0 . 0 3 8}$ & $\mathbf{0 . 0 1 5}$ & $\mathbf{0 . 3 1 3}$ & $\mathbf{0 . 0 1 7}$ \\
TX90p & $\mathbf{0 . 2 2 0}$ & $\mathbf{0 . 0 7 5}$ & $\mathbf{0 . 0 0 7}$ & $\mathbf{0 . 3 2 2}$ & $\mathbf{0 . 0 1 3}$ \\
TN90p & 0.108 & 0.064 & 0.103 & 0.154 & 0.239 \\
WSDI & $\mathbf{0 . 2 6 3}$ & $\mathbf{0 . 1 2 7}$ & $\mathbf{0 . 0 4 8}$ & $\mathbf{0 . 2 9 0}$ & $\mathbf{0 . 0 4 9}$ \\
DTR & $\mathbf{0 . 0 2 2}$ & $\mathbf{0 . 0 1 0}$ & $\mathbf{0 . 0 4 5}$ & $\mathbf{0 . 2 8 8}$ & $\mathbf{0 . 0 2 7}$ \\
RX1 & -0.241 & 0.248 & 0.340 & -0.078 & 0.556 \\
SDII & -0.007 & 0.020 & 0.740 & -0.026 & 0.858 \\
R10 & -0.026 & 0.075 & 0.730 & -0.005 & 0.986 \\
R20 & $\mathbf{0 . 0 7 9}$ & $\mathbf{0 . 0 3 6}$ & $\mathbf{0 . 0 3 4}$ & 0.263 & 0.058 \\
CDD & 0.113 & 0.289 & 0.699 & 0.082 & 0.543 \\
R95p & 0.439 & 1.120 & 0.698 & 0.035 & 0.803 \\
\hline
\end{tabular}

second part of the $20^{\text {th }}$ century was found. A significant positive trend, instead, is found in the annual maximum value of daily Tmin (TNX, Fig. 5), and (even if at boundary of statistical significance of the $0.1 \%$ ) in the percent of days when $\mathrm{Tmin}>90^{\text {th }}$ percentile (TN90p, Fig. 5). This indicates an increase in the summer night time temperature as confirmed by the rising trend of 4-5 days per decade in the number of tropical nights indicator (TR20, Fig. 5) when Tmin $>20^{\circ} \mathrm{C}$, in conformity with the results of other studies (Kostopoulou and Jones, 2005);

(iii) About Tmax extremes, an increasing tendency in the percentage of days when Tmax $>90^{\text {th }}$ percentile (TX90p, Fig. 5) is found. The annual number of very hot summer days with maximum temperatures higher than $35{ }^{\circ} \mathrm{C}$ (TX35) shows evidence of a stronger trend of about 6 days per decade. The Warm Spell Duration Indicator (WSDI, Fig. 5) reveals a significant trend of about 2-3 days per decade. Trends in the number of days when Tmax $>25^{\circ} \mathrm{C}$ (TX25, not shown), representative of change in spring and autumn seasons, are negligible. All these results are in agreement to other studies (Frich et al., 2002, Brunetti et al., 2004, Kostopoulou and Jones, 2005) even if the slope coefficients in this case indicate a stronger phenomenon; 
TR20

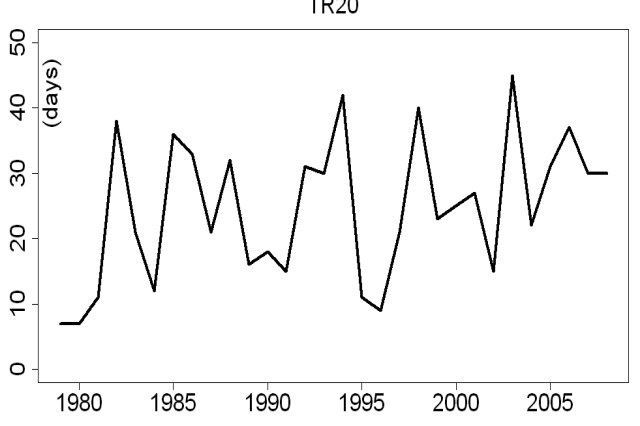

WSDI

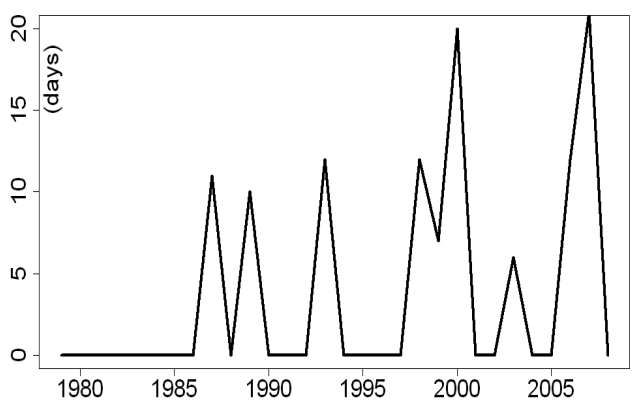

TX35

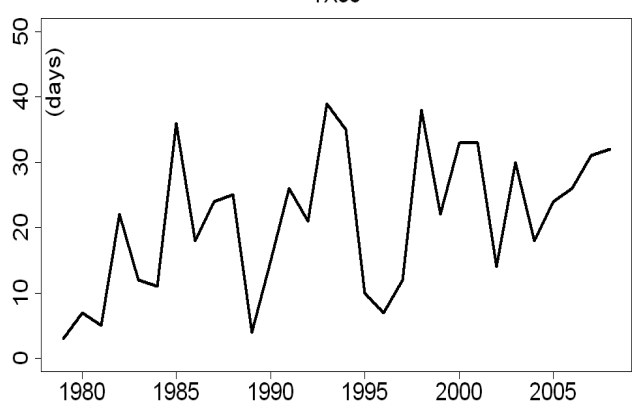

TX90p

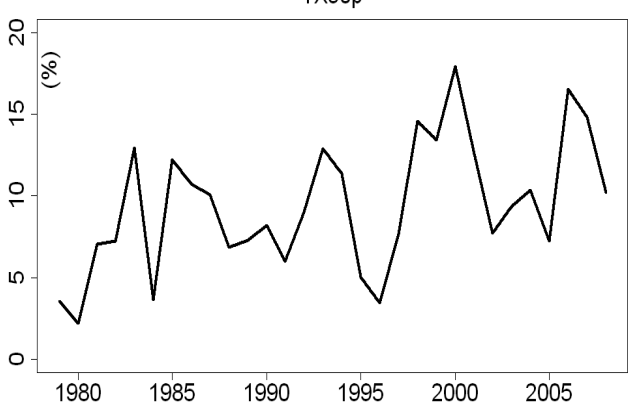

TNX

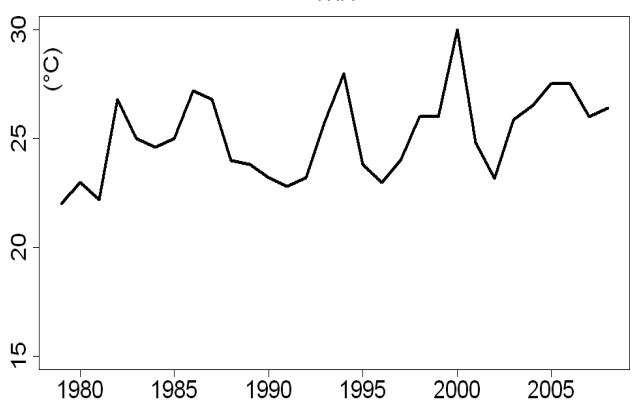

$\mathrm{R} 20$

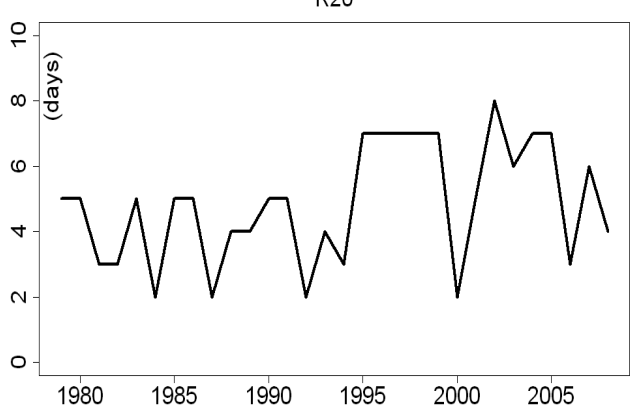

Figure 5. Temporal evolution of the extreme event indices in the last thirty years at 'Podere 124' (Capitanata, Italy).

(iv) With respect to precipitation, no extreme index shows evidences about trends. The reason is likely due to the high variability and also to the relatively brief length of the series. In fact, as demonstrated in other studies (Frich et al., 2002, Kostopoulou and Jones, 2005, Klein Tank, 2009), when several stations were compared, contrasting results were found. Whereas, some considerations can be made regarding yearly number of extreme intense wet days, with rainfall greater than 20 mm (R20, Fig. 5): it exhibits a statistical sig- nificant slope trend at the $95 \%$ confidence level. This is in agreement with the results of Brunetti et al. (2004). In fact, besides a reduction of the number of wet days in a longer period (1951-2000), they found a tendency towards an increase in precipitation intensity. It is worth mentioning the negligible slope significance of the number of consecutive dry days (CDD, not shown), an important index in desertification related scenarios, with a mean value of about 42 days per year and a peak of 85 days in 1997. 


\section{Conclusions}

In this study we analysed in detail the climate of a representative site of Capitanata plain (southern Italy) by using robust and suitable statistical techniques, in order to give effective information about actual climatic trends. The metadata found in the paper archive of our agro-meteorological stations and a suitable data quality control permitted us to avoid to take into consideration bad values due to manual human errors or sensor malfunctioning. In this way a very high quality, robust time series of data has been treated in our statistical analysis.

We stated that the increase in surface temperature is in particular due to the summer season, having an intensification of the number of heat waves. These results are more evident in maximum than in minimum temperature, indicating a possible anticipation of the summer season. However, this analysis needs more effort in order to evaluate the impacts in vegetation processes and consequences on yield. No significant trends was found in precipitation series, with except to a weakly increase in the number of the intense precipitation events.

These trends, even if significant, must be considered with precaution. In fact, they are only relative to the last 30 years, so it could be influenced by cycles at long time scale. Moreover, we quantified them by means of the slope estimation of a linear function, which could not be the most suitable for the best description of the phenomena.

Anyway, the results derived from this work should be used for a risk analysis on the actual agriculture. In particular the length of the growth crop cycle is affected by such a huge increase of temperatures, as well as the crop water requirements by the extreme events in precipitation regime.

\section{Acknowledgments}

This work is supported by Italian Ministry of Agriculture, Food and Forestry Policies under contract n. 209/7303/05 (AQUATER Project). Thanks to the Servizio Idrografico Nazionale for the supply of data used in quality control procedures. We thank also Vonella A.V. (CRA-SCA) for the supply of data registered at 'Podere 124' station.

\section{References}

Alexandersson H. 1986. A homogeneity test applied to precipitation data. J. Climatol., 6:661-675.

Beniston M., Stephenson D.B. 2004. Extreme climate events and their evaluation under changing climate conditions. Glob. Plan. Ch., 44:1-9.

Beniston M., Diaz H.F. 2004. The 2003 heat wave a san example of summers in a greenhouse climate? Observations and climate model simulations for Basel, Switzerland. Glob. Plan. Ch., 44:73-81.

Baigorria G.A., Jones J.W., Shin D.-W., Mishra A., O'Brien J.J. 2007. Assessing uncertainties in crop model simulations using daily bias-corrected Regional Circulation Model outputs. Clim. Res., 34:211-222.

Brunetti M., Buffoni L., Maugeri M., Nanni T. 2000. Trends of minimum and maximum daily temperatures in Italy from 1865 to 1996. Theor. Appl. Climatol., 66:49-60.

Brunetti M., Buffoni L., Mangianti F., Maugeri M., Nanni T. 2004. Temperature, precipitation and extreme events during the last century in Italy. Global and Planetary Change, 40:141-149.

Buishand T.A. 1982. Some methods for testing the homogeneity of rainfall records. J. Hydrol., 58:11-27.

De Martonne E. 1941. Nouvelle carte mondiale de l'indice d'ariditè. La meteorologie, 1:3-20.

Easterling D.R., Meehl G.A., Parmesan C., Changnon S.A., Karl T.R., Mearns L.O. 2000. Climate extremes: Observations, modeling, and impacts. Science, 289:2068-2074.

Frich P., Alexander L.V., Della-Marta P., Gleason B., Haylock M., Klein Tank A.M.G., Peterson T. 2002. Observed coherent changes in climatic extremes during the second half of the twentieth century. Climate Research, 19:193-212.

Gil-Alana L.A. 2008. Time trend estimation with breaks in temperature time series. Climatic Change, 89:325-337.

Hansen J., Sato M., Ruedy R., Lo K., Lea D.W., Medina-Elizade M. 2006. Global temperature change. The National Academy of Sciences of the USA, PNAS, 103, 39:14288-14293, http://www.pnas.org_cgi_doi_10.1073_ pnas.0606291103

Intergovernmental Panel on Climate Change. 2007. Climate Change 2007: Synthesis Report, http://www.i pcc.ch.

Jones P.D., Parker D.E., Osborn T.J., Briffa K.R. 2009. Global and hemispheric temperature anomalies land and marine instrumental records. In Trends: A Compendium of Data on Global Change. Carbon Dioxide Information Analysis Center, Oak Ridge National Laboratory, U.S. Department of Energy, Oak Ridge, Tenn., U.S.A. doi: 10.3334/CDIAC/cli.002.

Katz R.W. 2002. Techniques for estimating uncertainty in climate change scenarios and impact studies. Clim. Res., 20:167-185.

Kendall M.G. 1938. A new measure of rank correlation. Biometrika, 30:81-93. 
Klein Tank A.M.G., Konnen G.P. 2003. Trends in indices of daily temperature and precipitation extremes in Europe. Journal of Climate, 16:3665-3680.

Klein Tank A.M.K. 2008. European Climate Assessment \& Dataset (ECA\&D) - Algorithm Theoretical Basis Document (ATBD), http://eca.knmi.nl/

Klein Tank A.M.K., Zwiers F.W., Zhang X. 2009. Guidelines on Analysis of extremes in a changing climate in support of informed decisions for adaptation. Climate Data and Monitoring WCDMP-No. 72, WMOTD No. 1500.

Kostopoulou E., Jones P.D. 2005. Assessment of climate extremes in the Eastern Mediterranean. Meteorological and Atmospheric Physics, 89:69-85.

Mann H.B. 1945. Nonparametric tests against trend, Econometrica, 13:245-259.

Parmesan C., Root T.L., Willig M.R. 2000. Impacts of extreme weather and climate on terrestrial biota. Bull. Am. Met. Soc., 81/3:443-450.

Peterson T.C., Zhang X., Brunet-India M., VázquezAguirre J.L. 2008. Changes in North American extremes derived from daily weather data, J. Geophys. Res., 113, D07113, doi:10.1029/2007JD009453.
Pettitt A.N. 1979. A non-parametric approach to the change-point detection. Appl. Statist., 28:126-135.

R Development Core Team. 2008. R: A language and Environment for Statistical Computing, R Foundation for Statistical Computing, Vienna, Austria. URL: http://www.R-project.org/.

Rana G., Rinaldi M., Introna M. 2004. Metodologie e algoritmi per il controllo di qualità di dati orari e giornalieri acquisiti da una rete agrometeorologica: applicazioni alla rete lucana SAL, Rivista Italiana di Agrometeorologia, Anno 9, 1:14-23.

Sneyers R. 1990. On the Statistical Analysis of Series of Observation. WMO, Technical Note N. 143, Geneve, 192 pp.

Walter H., Lieth H. 1960. Klimadiagramm Weltatlas. G. Fischer, Jena.

Wijngaard J.B., Klein Tank A.M.G., Konnen G.P. 2003. Homogeneity of $20^{\text {th }}$ century European daily temperature and precipitation series. Int. J. Climatol., 23:679-692.

Zhang X., Yang F. 2004. RClimDex (1.0) User Manual. Available from http://cccma.seos.uvic.ca/ETCCDMI/ software.html. 